\title{
Seismic risk assessment for the Historical center of Quito and Validation
}

\author{
Indyra Dayanne Delgado, Emily Fernanda Cabay, Juan Carlos Pantoja, USFQ
}

Copyright 2021, SBGf - Sociedade Brasileira de Geofísica

This paper was prepared for presentation during the $17^{\text {th }}$ International Congress of the Brazilian Geophysical Society held in Rio de Janeiro, Brazil, 16-19 August 2021.

Contents of this paper were reviewed by the Technical Committee of the $17^{\text {th }}$ International Congress of the Brazilian Geophysical Society and do not necessarily represent any position of the SBGf, its officers or members. Electronic reproduction or storage of any part of this paper for commercial purposes without the written consent of the Brazilian Geophysical Society is prohibited.

\section{Abstract}

Quito is the capital of Ecuador and due to its importance for the country, it requires an updated seismic risk assessment study that addresses models of exposure, seismic hazard, and structure vulnerability.

The purpose of this paper is to evaluate the seismic risk assessment model of the Historical Center of Quito (from now HCQ) by comparing it with collected information from previous punctual seismic events. To establish the seismic hazard model, we based on probabilistic studies of two punctual past seismic events. The first one was on March 5, 1987, and the second on August 11, 1990. In addition, the Ground Motion Prediction Equations (GMPE) used in this study are: AkkarBommer2010 (Akkar \& Bommer, 2010), BooreAtkinson2008 (Boore \& Atkinson, 2008), and ZhaoEtAl2006 (Zhao et al, 2006). The exposure model was generated from the Quito Geoportal and the Metropolitan Cadastre Data Base, compiling information such as the construction material, the lateral load resistance system, among others for 1183 residential and commercial structures. On the other hand, the vulnerability parameter was analyzed through fragility curves that determine the economic losses of 12 types of structures defined and developed by Martins and Silva (2020). The seismic risk assessment model was built by using OpenQuake software developed by the Global Earthquake Model association (GEM).

The model was validated by comparing it with the PGA obtained from the seismic catalogs. Both the model and reality show a PGA of $0.06 \mathrm{~g}$ for the 1987 event and $0.18 \mathrm{~g}$ for the 1990 event.

The results of the analysis showed structural losses of 2'272,082.5 USD for the 1987 event and 288,283 USD for the 1990 event, where $61.5 \%$ (1987) and $57.12 \%$ (1990) of the losses were to structures whose lateral load resistant system is not ductile and are from 1 to 4 stories, mainly built with Adobe walls.

\section{Introduction}

The analysis of seismic risk in Ecuador is necessary mainly because of Ecuador's location in the Pacific Ring of Fire region, where a large percentage of seismic energy is released in the form of earthquakes. The main source of tectonic earthquake generation is the subduction caused by the Nazca plate within the South American plate and the earthquakes are characterized by hypocenter subduction earthquakes in the inter-Andean valley.

The capital city, Quito, located at an altitude of 2,800 meters above sea level with a population of approximately $2,600,000$ inhabitants, being the city with the highest population density for the year 2020 which has also grown rapidly and in a disorderly manner, with poor quality constructions that make it vulnerable when facing a seismic event. The city is set in the Quito Fault System (QFS), which extends for a length of $60 \mathrm{~km}$ along with the Inter-Andean Depression in northern Ecuador. This fault system is associated with seismic micro activities of an average magnitude of $4.0 \mathrm{Mw}$. According to Alvarado et al (2014), the earthquakes that occur in this area are mainly from reverse failure mechanisms.

The latest seismic risk analysis project developed for Quito is "The Quito, Ecuador, Earthquake Risk Management Project." Which is a cooperative pilot project done in the year 1994 for the reduction of urban earthquake risk in developing countries. In this analysis project, it was concluded that the city of Quito is currently unprepared for a major earthquake, resulting in significant human and economic losses (Yépez, 2001).

This document focuses on the HCQ whose structures are mainly built of adobe or brick, as well as non-engineered constructions. For this reason, information is compiled to estimate probable damage that could occur in the structures in the event of an earthquake. To evaluate seismic risk, exposure, hazard, and vulnerability study is carried out, characterizing the probability of occurrence of certain seismic intensities in a given time using the methodology of the GEM association.

Two seismic scenarios were chosen to validate the calculations done by the OpenQuake software CITA. The 1987 and 1990 earthquakes were chosen for this study because it is known that they caused great structural damage to the HCQ buildings, in the same way, real data from the seismic catalogs are available and can be compared with the results of the modeling of this study.

\section{Method}

\section{Global Earthquake Model}

The GEM association created an open-source software called OpenQuake, which is used for this study for seismic risk estimation. In addition, it calculates scenarios, probabilistic analyses, hazard curves, and ground motion fields through fault modeling. 


\section{Exposure Model}

The methodology to obtain the exposure model and to visualize it in the QGIS software starts with an external geo-referenced database obtained from the Quito Geoportal, from which the map of buildings of the HCQ is expressed in the number of floors. Furthermore, the year of construction, construction area, appraisal, and front frontage length are obtained from the Metropolitan Cadastre System. Also, from the Land Use and Occupancy Plan of the City, the property number identification is obtained. In addition, the information required to generate it depends on the type of model, in this case, the platform of Google Earth was used to determine the wall and roof materials as well as the lateral load resistant system.

The delimitation for the exposure model covers a total of 2157 structures located in the central core and the western enveloping zone of the $\mathrm{HCQ}$, as shown in figure 1.

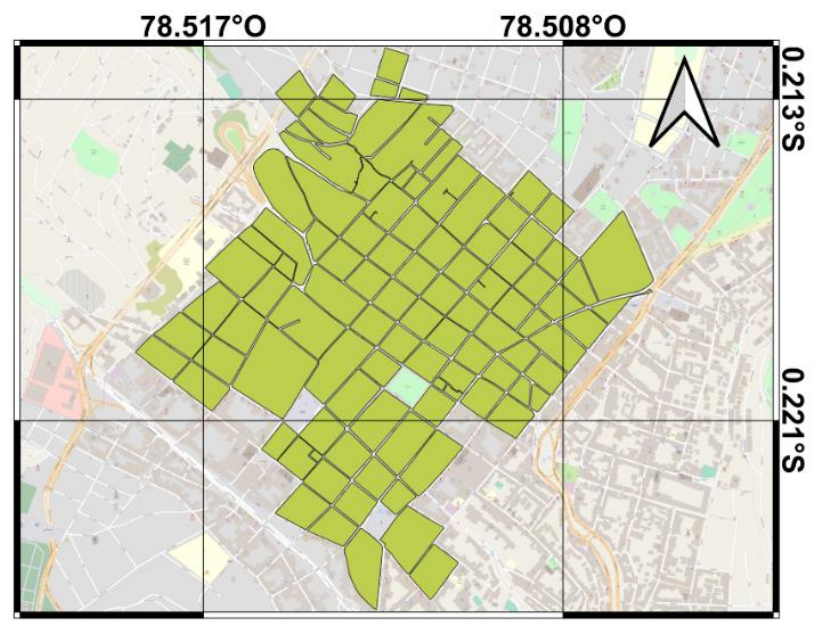

Figure 1- Delimitation of the Historic Center of Quito

According to the information collected from the external databases, the exposure model has three types of occupancies. The first is for residential use with a singlefamily house, depicted as "RES1". The second is for residential use, but with several apartments, "RES2". Finally, there is the mixed-use, i.e., residential, and commercial, which is called "MIX1".

The percentage of buildings in the HCQ for the three occupancies types are: $8.16 \%$ RES2, $20.63 \%$ for MIX1, $26.05 \%$ for RES1 which represents $54.84 \%$ of the total; and $45.16 \%$ is excluded from the study as it belongs to structures used purely for commercial, institutional, and public purposes. That is, of the 2157 structures previously considered, the study will now focus on the remaining 1183.

The predominant construction materials in the HCQ are brick with $41.17 \%$, cast-in-place concrete block with $34.57 \%$, and adobe with $24.26 \%$ of the structures. Of the 1183 structures analyzed in the study, most of the constructions have 2 stories with $49.79 \%$. Likewise, $27.73 \%$ were 3 -story , $14.96 \%$ were 1 -story, $5.41 \%$ were 4 - story and $2.11 \%$ were 5, 6 and 7 -story. In the HCQ, the vast majority of constructions are of unreinforced masonry with $68.22 \%$, the reinforced concrete frame system with $30.68 \%$, and flat slabs with $1.1 \%$, as shown in figure 2 .
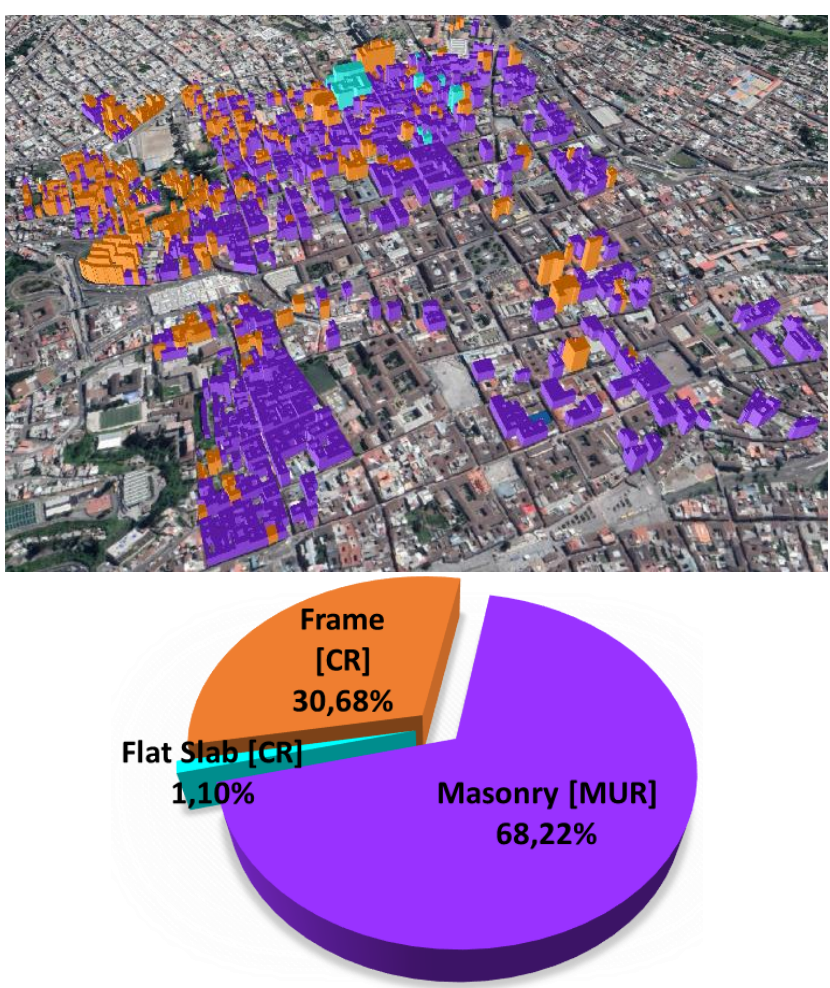

Figure 2- Spatial distribution of the lateral load resistance system of the structures in the HCQ

\section{Seismic Hazard Model}

To understand the behavior of the ground in a punctual seismic event, maps of the scenarios are modeled using OpenQuake software where the damage caused by a specific earthquake can be observed. To define the rupture plane model we used the information recorded for the rupture, which was obtained from seismic catalogs as shown in table 1 (EPN, 2020).

Table 1-Rupture parameters for punctual seismic events of 1987 and 1990.

\begin{tabular}{lll}
\hline Seismic event & $\mathbf{1 9 8 7}$ & $\mathbf{1 9 9 0}$ \\
\hline Strike & $6.07^{\circ}$ & $323.00^{\circ}$ \\
\hline Dip & $75.03^{\circ}$ & $45.00^{\circ}$ \\
\hline Rake & $45.05^{\circ}$ & $52.00^{\circ}$ \\
\hline $\begin{array}{l}\text { Magnitude } \\
\text { (Mw) }\end{array}$ & 6.9 & 5 \\
$\begin{array}{l}\text { Latitude and } \\
\text { Longitude }\end{array}$ & $-77.84^{\circ} ;-0.087^{\circ}{ }^{\circ}$ & $-78.43^{\circ} ;-0.039^{\circ}$ \\
\hline Depth & $12 \mathrm{Km}$ & $15 \mathrm{Km}$
\end{tabular}

For the case of the HCQ, three GMPE's are considered: Akkar and Bommer 2010, Boore and Atkinson 2008, and Zhao et al. 2006, these were established in the study of seismic hazard in Quito as the ones that best characterize 
the fault behavior in the study area (Cañizares \& Singaucho, 2017).

To model ground motion map, the site conditions corresponding to a soil type which has medium stiffness characteristics, with a rock that meets the shear wave velocity criterion, which is a Type $C$ soil according to NEC15 (NEC, 2015). The maximum distance from hypocenter to exposed elements was determined as 300 $\mathrm{km}$ to include all the buildings in the $\mathrm{HCQ}$, for the case of variability a truncation level of 3 is used, and for not considering variability a truncation level of 0 is used. The site conditions are shown in table 2.

Table 2- Modelation parameters of site conditions for the $H C Q$

\begin{tabular}{ll}
\hline Vs $\mathbf{3 0}$ & $760 \mathrm{~m} / \mathrm{s}$ \\
\hline $\begin{array}{l}\text { Minimum depth vs30 vs30 } \\
\mathbf{1 . 0} \mathbf{~ k m} / \mathbf{s}(\mathbf{z 1 . 0})\end{array}$ & $100 \mathrm{~m}$ \\
\hline $\begin{array}{l}\text { Minimum depth vs } \mathbf{3 0} \geq \mathbf{2 . 5} \\
\text { km/s (z2.5) }\end{array}$ & $2 \mathrm{Km}$ \\
\hline GMPE & Determined \\
\hline IMT & PGA \\
\hline Correlation Model & $\mathrm{JB} 2009$ \\
\hline Truncation Level & 3 and 0 \\
\hline $\begin{array}{l}\text { Maximum distance from } \\
\text { hypocenter to exposed } \\
\text { elements }\end{array}$ & $300 \mathrm{Km}$ \\
\hline \begin{tabular}{l} 
No. of ground motion fields \\
\hline
\end{tabular} & 250 \\
\hline
\end{tabular}

\section{Vulnerability curves}

For this study, the information obtained from databases related to the structural characteristics such as material, lateral load resisting system, level of ductility, story numbers were used to characterize the buildings according to the GEM Foundation nomenclature which is shown in table 3. Based on these typologies the Martins and Silva curves were used, as these curves are open-source (Martins \& Silva, 2020).

Table 3- Structural typologies of buildings in HCQ according to GEM nomenclature

\begin{tabular}{ll}
\hline Nomenclature & Building characteristic \\
\hline MUR & Unreinforced Masonry \\
\hline CR & Reinforced Concrete \\
\hline MUR-ADO & Adobe Wall \\
\hline LFM & Moment frame \\
\hline LFINF & Infilled frame \\
\hline LWAL & Wall \\
\hline DUL & Low Ductility \\
\hline DUM & Medium Ductility \\
\hline DUH & High Ductility \\
\hline DNO & Non-Ductile \\
\hline
\end{tabular}

Twelve vulnerability models are considered for this study, classifying them according to their lateral load resisting system, wall material, ductility, and the number of floors as shown in table 4 as well as their percentage relative to the total amount of structures classified.

Table 4-Percentage of buildings in $H C Q$ according to typology and their GEM nomenclature

\begin{tabular}{lll}
\hline Types & Nomenclature & $\begin{array}{l}\text { \% of } \\
\text { buildings } \\
\text { in HCQ }\end{array}$ \\
\hline Type 1 & CR_LFINF-DUL_H3 & $5.41 \%$ \\
\hline Type 2 & CR_LFINF-DUM_H2 & $17.33 \%$ \\
\hline Type 3 & CR_LFINF-DUM_H3 & $2.45 \%$ \\
\hline Type 4 & CR_LFINF-DUM_H5 & $2.79 \%$ \\
\hline Type 5 & CR_LFINF-DUM_H6 & $3.80 \%$ \\
\hline Type 6 & CR_LFM-DUM_H3 & $2.62 \%$ \\
\hline Type 7 & CR_LFM-DUM_H4 & $0.08 \%$ \\
\hline Type 8 & CR_LWAL-DUL_H1 & $0.08 \%$ \\
\hline Type 9 & MUR_SAmerica_LWAL- & $16.40 \%$ \\
& DNO_H1 & \\
\hline Type & MUR_SAmerica_LWAL- & $7.86 \%$ \\
$\mathbf{1 0}$ & DNO_H3 & $30.94 \%$ \\
\hline Type & MUR- & \\
$\mathbf{1 1}$ & ADO_SAmerica_LWAL- & \\
\hline & DNO_H2 & $10.23 \%$ \\
\hline Type & MUR- & \\
\hline & ADO_SAmerica_LWAL- & \\
\hline
\end{tabular}

\section{Seismic Risk Model}

The temporal and spatial overlap of exposure, hazard, and vulnerability is modeled using the OpenQuake software, developed by GEM. To model the scenario risk assessment, Openquake calculates damage or asset loss distribution statistics for a group of buildings from a single seismic rupture scenario. To define it, the rupture information is needed, in this case from both the 1987 and 1990 seismic event planes, defined in the hazard chapter. Likewise, the exposure model, which has structural information of the HCQ buildings, is used to define the hazard site. The site parameters used for this assessment are the same used in hazard calculation, however, in this case, 2000 ground motion fields were used which is the convergence number indicated by the actual statistics.

\section{Results \\ Hazard seismic model}

For the 1990 event, a PGA of $0.18 \mathrm{~g}$ was measured at the epicenter of the earthquake in the city of Pomasqui; whereas for the 1987 event, according to the seismic catalogs, the PGA was $0.06 \mathrm{~g}$ measured in the city of Quito (Singaucho, 2009). From the analysis, it is observed that the results of intensities obtained in this modeling validate this study because when compared with the real seismic catalogs show very approximate results.

Table 5- Comparison between experimental data and measures obtained in the models and error percentage calculated 


\begin{tabular}{llll}
\hline & Akkar2010 & Boore2008 & Zhao2006 \\
\hline $\begin{array}{l}\text { Intensity } \\
\text { 1990 [g] }\end{array}$ & 0.2 & 0.21 & 0.055 \\
\hline Error & $11.1 \%$ & $16.7 \%$ & $69.4 \%$ \\
\hline $\begin{array}{l}\text { Intensity } \\
\mathbf{1 9 8 7} \text { [g] }\end{array}$ & 0.06 & 0.08 & 0.08 \\
\hline Error & $0 \%$ & $33 \%$ & $33 \%$ \\
\hline
\end{tabular}

As can be seen in Table 5, the GMPE that best approximates the real data of intensities is AkkarBommer2010, since it represents the lowest percentage error in both punctual seismic events compared to the other GMPEs and since it is the one used for crustal earthquakes.

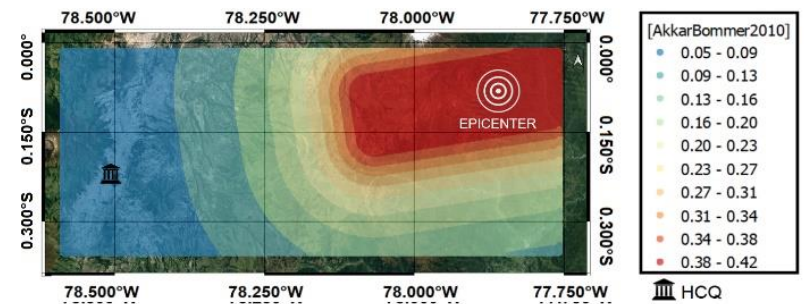

Figure 3 - Seismic hazard model for the 1987 without variability including the epicenter and the $H C Q$

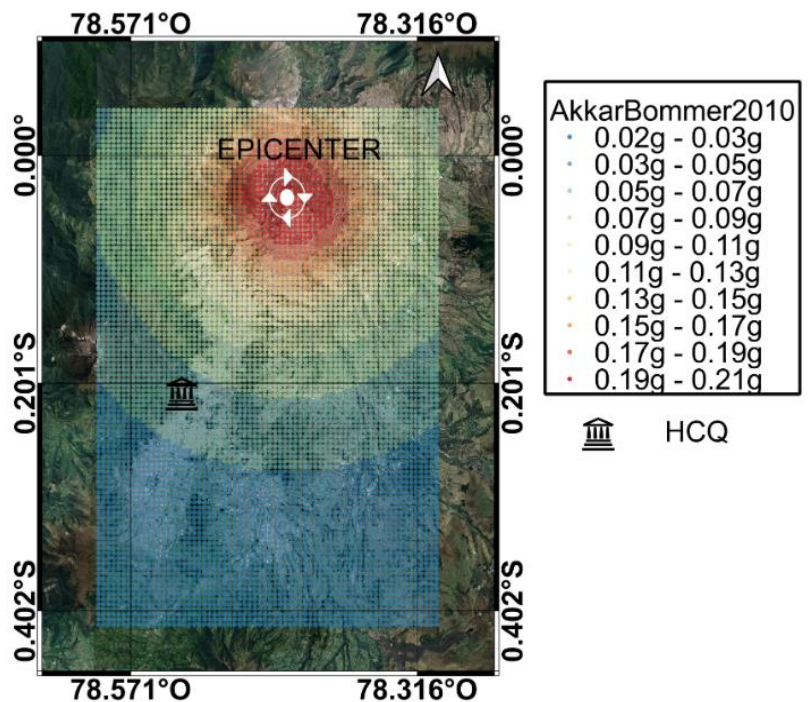

Figure 4 - Seismic hazard model for the 1990 without variability including the epicenter and the $H C Q$

\section{Seismic Risk Model}

Once the risk model has been validated with the results of the measurements of past events, the economic asset losses caused by the events are now estimated. The results obtained for information on the economic losses incurred in HCQ during the events are shown in Table 6 for the three GMPEs. As it was previously defined in the seismic hazard model that the equation that best fits the real data in the study area is AkkarBommer2010, comparisons will be made based on the results of this GMPE.

In 1990, the economic losses that occurred in the city of Pomasqui were 65,000 USD (IGEPN, 2011), in comparison, the economic losses caused by the current buildings that exist in the HCQ would produce losses of 288,283 USD, a figure that exceeds 4.5 times those that occurred in Pomasqui in 1990.

Table 6- Asset Losses according to GMPE for HCQ buildings

\begin{tabular}{lll}
\hline GMPe & $\begin{array}{l}\mathbf{1 9 9 0} \text { event } \\
\text { USD }\end{array}$ & $\begin{array}{l}\mathbf{1 9 8 7} \text { event } \\
\text { USD }\end{array}$ \\
\hline Akkar2010 & 288,283 & 2 2272,082.5 \\
\hline Boore2008 & 138,053 & $2^{\prime} 276,454.8$ \\
\hline Zha02006 & 225,556 & $2^{\prime} 819,845.5$ \\
\hline
\end{tabular}

Figure 5 shows that for this seismic risk study, the typologies with the highest losses in the calculations for both events are type 11 and type 12 . These typologies correspond to structures of an unconfined, unreinforced masonry lateral resistance system for low-rise structures built out of adobe material for non-ductile structures.

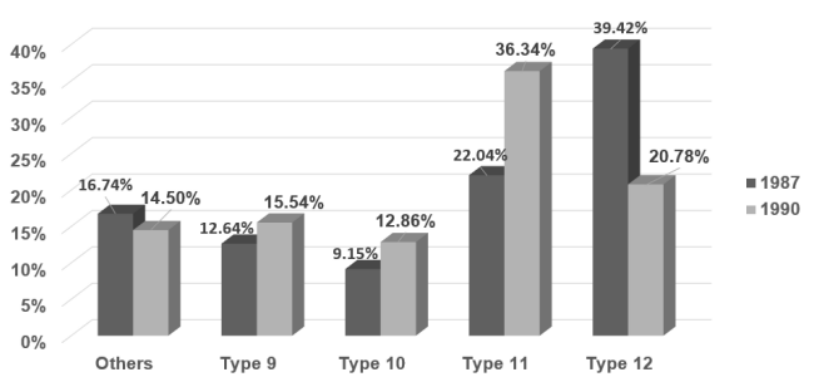

Figure 5- Comparison of structural losses per typology for the events of 1987 and 1990

\section{Conclusions}

An exposure model was obtained, and the collection of information showed that the predominant wall material $(41.17 \%)$ is brick. In addition, the structures were classified by their structural system, being unreinforced masonry, the highest percentage with $68.22 \%$ of the structures. This is worrisome because they perform well in compression, but are damaged by lateral loads, such as earthquakes. In addition, $73.46 \%$ of the structures studied do not have ductility. In other words, most of the structures do not have a great capacity to deform beyond the elastic range and lose their strength, which makes the $\mathrm{HCQ}$ a highly vulnerable area to seismic events.

The hazard study focuses on the comparison of real data of two punctual events with the results of the modeling done in OpenQuake. The AkkarBommer2010 GMPE was found to represent the lowest percentage error for both punctual events among the three GMPEs used in the modeling with an error of $0 \%$ for the 1987 event and $11.10 \%$ for the 1990 event. For this reason, it was chosen as the equation that best represents the modeling results.

The third parameter is seismic vulnerability, which helped to understand the losses in buildings caused by earthquakes, showing that the greater the intensity, the greater the losses. Finally, the seismic risk yielded 
2 '272,082.5 USD of structural losses for the 1987 event and 288,283 USD for the 1990 event, in both cases for the AkkarBommer2010 equation. The construction typologies that presented $61.46 \%$ (1987) and $57.12 \%$ (1990) of the losses are adobe walls and a percentage of $21.79 \%$ (1987 event) and $28.40 \%$ (1990 event) are brick walls and it should be emphasized that the structures with higher losses are from 1 to 3 stories. This is since their dynamic response depends on their stiffness, ductility, and resistance. However, these structures do not have ductility and their wall material is very old and tends to collapse in the event of ground shaking. In addition, they present shear failures due to cracking, generating fissures, and structural damage.

These results reflect that there could be millions of dollars of structural losses in structures that are currently dispersedly located on the HCQ, so. they are not found in a single place by typology. So, it is necessary to improve construction habits. It is needed to reinforce the non-ductile structures in the study area. In addition, it is important to carry out a more in-depth study of the site conditions at the micro zonation level, to reduce the uncertainties not verified in this study.

\section{References}

AKKAR, S., \& BOMMER, J. J. 2010. Empiral Equations for the Prediction of PGA, PGV, and Spectral Acceleration in Europe, the Mediterranean Region, and the Middle East. Seismological Research Letters, 81(2), 195-2006.

ALVARADO, A. AUDIN, L., NOCQUET, J., LAGREULET, S., SEGOVIA, M., FONT, Y., QUIDELLEUR, X. 2014. Active tectonics in Quito, Ecuador, assessed by geomorphological studies, GPS data, and crustal seismicity. Tectonics, 10.1002/2012TC003224.

BOORE, D. M., \& ATKINSON, G. M. 2008. Ground-Motion Prediction Equations for the Average Horizontal Component pf PGA, PVD and 5\%-Damped PSA at Spectral Periods between 0.01s and 10.0s. Earthquake Spectra, 24(1), 99-138.

CAÑIZAREZ, F., \& SINGAUCHO, J. 2017. EQUATIONS OF ATTENUATION COMPATIBLE WITH THE QUITO FAULT SYSTEM GMPEs.

EPN. 2020. Instituto Geofísico. Available at: https://www.igepn.edu.ec/

GEM. 2020. Global Earthquake Model Foundation. Available at: https://www.globalquakemodel.org/

MARTINS, L., \& SILVA, V. 2020. Development of a Fragility and Vulnerability Model for Global Seismic Risk Analyses. Bulletin of Earthquake Engineering.

NORMA ECUATORIANA DE LA CONSTRUCCIÓN. 2015. Capítulo NECSE-DS. Peligro Sísmico Siseño Sismo Resistente.

SINGAUCHO, J. 2009. Mapa de máximas intensidades sísmicas del Ecuador. Criterios estructurales para mejorar la estimación de intensidades. Escuela Politécnica Nacional.
YÉPEZ, F. 2001. Últimos avances en la evaluación del riesgo sísmico de Quito y futuros proyectos de mitigación. Memorias del seminario "Gestión de riesgos y prevención de desastres". FLACSO, COOPI, 16-28.

ZHAO, J. X., ZHANG, J., ASANO, A., OHNO, Y., OOUCHI, T., TAKAHASHI, T., \& FUKUSHIMA, Y. 2006. Attenuation relations of strong ground motion in Japan using site classification based on predominant period. Bulletin of the Seismological Society of America, 96(3), 898-913.

NORMA ECUATORIANA DE LA CONSTRUCCIÓN (NEC, 2014). Capítulo NECSE-DS. Peligro sísmico Diseño Sismo Resistente.

IGEPN. (2011). Sismo De Pomasquí-10 de agosto de 1990. Available at IGEPN: https://www.igepn.edu.ec/servicios/noticias/466-sismo-depomasqu\%C3\%AD-10-de-agosto-de1990\#: :text=El\%2010\%20de\%20agosto\%20de,al\%20No reste\%20del\%20aeropuerto\%20de 